\title{
ALTERAÇÕES FISIOLÓGICAS E BIOQUÍMICAS EM SEMENTES DE Pterogyne nitens Tull. DURANTE O ENVELHECIMENTO ARTIFICIAL ${ }^{1}$
}

\author{
Glauciana da Mata Ataíde ${ }^{2}$, Andressa Vasconcelos Flores ${ }^{3}$, Eduardo Euclydes de Lima e Borges ${ }^{2}$
}

\section{ABSTRACT \\ PHYSIOLOGICAL AND BIOCHEMICAL \\ CHANGES IN Pterogyne nitens Tull. SEEDS DURING THE ARTIFICIAL AGING PROCESS}

The accelerated aging test is usually used to evaluate seeds vigor and quality. This study aimed to investigate and establish relations among deterioration, physiological changes, and catalase enzyme activity, during the artificial aging process of Pterogyne nitens seeds. So, P. nitens seeds with and without dormancy overcoming, with the application of concentrated sulfuric acid (95-99\%), for 10 minutes, were exposed to the accelerated aging test, for $0,24,48$, and 72 hours, determining the germination percentage, lipids peroxidation, and catalase enzyme activity. The artificial aging process significantly affected the viability and vigor seeds, after a previous dormancy overcoming, with a decrease in germination and catalase enzyme activity and an increase in lipids peroxidation, during the aging process. For seeds that did not overcome dormancy, no relation among artificial aging, physiological changes, and enzyme activity was observed, so that dormancy acts as a protective mechanism for seeds oxidative stress.

KEY-WORDS: Seeds deterioration; catalase enzyme; lipid peroxidation; germination.

\section{INTRODUÇÃO}

A pesquisa a respeito da utilização de testes de vigor, para se avaliar a qualidade fisiológica de sementes florestais, tem crescido nos últimos anos, devido à objetividade e rapidez com que são conduzidos e à obtenção de respostas de forma segura e eficiente.

O teste de envelhecimento acelerado foi desenvolvido por Delouche (1965) e baseia-se no princípio de que sementes submetidas a temperatura e umidade relativa elevadas têm a deterioração aumentada, re-

\section{RESUMO}

O teste de envelhecimento acelerado é utilizado para avaliar o vigor e a qualidade de sementes. O presente trabalho teve como objetivo investigar e estabelecer relações entre a deterioração, alterações fisiológicas e atividade da enzima catalase, durante o envelhecimento artificial de sementes de Pterogyne nitens. Para tanto, sementes de P. nitens sem e com superação da dormência, por meio da aplicação de ácido sulfúrico concentrado (95-99\%), durante 10 minutos, foram submetidas ao teste de envelhecimento acelerado, por 0, 24, 48 e 72 horas, determinando-se a percentagem de germinação, peroxidação de lipídios e atividade da enzima catalase. O envelhecimento artificial afetou significativamente a viabilidade e vigor das sementes, após prévia superação da dormência, observando-se decréscimo na germinação e na atividade da enzima catalase e aumento na peroxidação de lipídios, durante o envelhecimento. Nas sementes que não tiveram a dormência superada, não foi observada relação entre o envelhecimento artificial, alterações fisiológicas e atividade da enzima, de forma que a dormência atua como um mecanismo protetor do estresse oxidativo nas sementes.

PALAVRAS-CHAVE: Deterioração de sementes; enzima catalase; peroxidação de lipídio; germinação.

sultando na queda de sua qualidade. Desta forma, o estudo dos mecanismos de envelhecimento de sementes e a determinação de indicadores de sua qualidade podem resultar em benefícios para a preservação da biodiversidade genética das espécies, em bancos de germoplasma (Mira et al. 2011).

Em sementes mais deterioradas, há menor integridade das membranas e, como consequência, ocorre o extravasamento do conteúdo celular para o meio, constatado pelo aumento da quantidade de lixiviados, durante o processo de embebição (Kruse et

1. Trabalho recebido em dez./2011 e aceito para publicação em mar./2012 ( ${ }^{\circ}$ registro: PAT 16497).

2. Universidade Federal de Viçosa, Centro de Ciências Agrárias, Departamento de Engenharia Florestal, Viçosa, MG, Brasil. E-mails: glaucianadamata@yahoo.com.br, elborges@ufv.br.

3. Instituto Federal de Educação, Ciência e Tecnologia de Mato Grosso, Campus Cáceres, Cáceres, MT, Brasil.

E-mail: andressafloressm@yahoo.com.br. 
al. 2006). Além disto, na deterioração das sementes, há aumento na peroxidação de lipídios, a qual resulta em danos à membrana e geração de subprodutos tóxicos (Schwember \& Bradford 2010).

O processo de peroxidação lipídica resulta na formação do malonaldeído (MDA), produto secundário durante a oxidação de ácidos graxos poli-insaturados, cuja determinação, em amostras biológicas, é indicativa do grau de estresse oxidativo presente (Lima \& Abdalla 2001).

Em condições fisiológicas normais, o estresse oxidativo produzido é combatido por um complexo sistema de defesa antioxidante, relacionado ao aumento da produção e ativação de metaloenzimas, dentre as quais encontra-se a catalase (CAT) (Bowler et al. 1992, Scandalios 1993), que catalisa a conversão do peróxido de hidrogênio $\left(\mathrm{H}_{2} \mathrm{O}_{2}\right)$ em água $\left(\mathrm{H}_{2} \mathrm{O}\right)$, protegendo as células de danos oxidativos (Scandalios 2005). Durante o processo de deterioração das sementes, ocorre decréscimo na atividade desta enzima, pela sua inativação progressiva ou redução e paralisação de sua síntese (Marcos Filho 2005). Segundo Demirkaya et al. (2010), a diminuição geral na atividade da CAT na semente diminui a capacidade respiratória, reduzindo o fornecimento de energia (ATP) e assimilados, para a germinação da semente.

Em sementes de Melanoxylon brauna, foram observados decréscimos significativos na atividade da enzima CAT, no eixo embrionário e nos cotilédones, durante os envelhecimentos natural e artificial, comprovando que o envelhecimento artificial possui mecanismo similar ao do envelhecimento natural, durante a deterioração em sementes da espécie (Corte et al. 2010). Para Triticum aestivum, a redução do vigor das sementes, durante o envelhecimento artificial, foi associada à diminuição da atividade das enzimas CAT e do superóxido dismutase, relacionadas ao aumento na relação rafinose/sacarose, resultantes da deterioração das sementes (Lehner et al. 2008).

O amendoim do campo (Pterogyne nitens Tull.) é uma espécie florestal perenifólia a semicaducifólia, pertencente à família Leguminosae Caesalpinoidea, com ocorrência desde o Ceará até o oeste do Estado de Santa Catarina, principalmente no Cerrado (Silva et al. 1995). Tem sido recomendada para reposição de áreas degradadas e arborização de vias urbanas e rodovias, devido ao seu alto valor ornamental (Carvalho 1994), e encontra-se classificada como espécie em perigo de extinção (Nogueira et al. 1986, FAO 1996). Estudos dos processos fisiológicos das sementes são o ponto de partida para a utilização racional da espécie, fator preponderante para o sucesso dos programas de produção das mudas a serem utilizadas para os diversos fins.

Neste contexto, o objetivo do presente trabalho foi investigar e estabelecer relações entre a deterioração, alterações fisiológicas e atividade da enzima catalase, durante o envelhecimento artificial de sementes de Pterogyne nitens.

\section{MATERIAL E MÉTODOS}

O estudo foi desenvolvido no Laboratório de Análise de Sementes Florestais da Universidade Federal de Viçosa, com sementes de Pterogyne nitens colhidas na região de Viçosa (MG), em abril de 2010. Durante o beneficiamento, foram eliminadas as sementes imaturas, deterioradas ou danificadas, sendo as remanescentes acondicionadas em sacos plásticos e armazenadas em câmara, à temperatura de $20^{\circ} \mathrm{C}$, até o momento de se iniciarem as avaliações.

A superação da dormência tegumentar das sementes de $P$. nitens foi realizada pela aplicação de ácido sulfúrico concentrado (95-99\%), durante 10 minutos (Nassif \& Perez 1997). Sementes sem prévia superação da dormência e sementes com a dormência superada foram testadas neste trabalho, sendo submetidas ao teste de envelhecimento acelerado. Para tanto, as sementes foram colocadas sobre tela de alumínio, em caixas gerbox contendo $40 \mathrm{~mL}$ de água destilada, as quais foram tampadas e mantidas em câmara de envelhecimento artificial, à temperatura de $40^{\circ} \mathrm{C}$ e, aproximadamente, $100 \%$ de umidade relativa do ar, por 24, 48 e 72 horas $\left(\mathrm{T}_{24}, \mathrm{~T}_{48}\right.$ e $\mathrm{T}_{72}$, respectivamente, e testemunha $-\mathrm{T}_{0}$ ).

Decorridos os períodos de envelhecimento, as sementes foram submetidas às seguintes determinações:

Percentagem de germinação - as sementes foram tratadas com o fungicida Captan $0,5 \%$, por três minutos, e colocadas sobre duas folhas de papel de filtro tipo germitest, umedecido com água destilada equivalente a 2,5 vezes o seu peso, em placas de Petri, sendo mantidas por 10 dias em germinador, a $25^{\circ} \mathrm{C}$, sob luz constante, proporcionada por quatro lâmpadas de $20 \mathrm{~W}$, tipo luz do dia. Foram consideradas germinadas as sementes que emitiram raiz $(>2 \mathrm{~mm})$. A percentagem de germinação foi determinada pela 
contagem diária das sementes e os resultados foram expressos em percentagem média. Foram utilizadas cinco repetições de 20 sementes cada;

Peroxidação de lipídios - foi avaliada por meio da determinação do índice de ácido tiobarbitúrico (TBA), segundo Araújo (1995). Para isto, 0,250 g de semente seca e moída foram homogeneizados com 2,0 mL de ácido tricloroacético (TCA). A mistura foi combinada com $3 \mathrm{~mL}$ de solução TBA $0,5 \%(\mathrm{p} / \mathrm{v})+$ TCA $20 \%(\mathrm{p} / \mathrm{v})$ e aquecida por 35 minutos, para desenvolvimento da coloração. Após resfriamento, a peroxidação dos lipídios foi determinada espectrofotometricamente, a $532 \mathrm{~nm}$ e $600 \mathrm{~nm}$, obtendo-se, assim, os valores de absorbância líquida. Os resultados foram expressos em miligramas de malonaldeído (MDA) (mmol g-1 de amostra), após a conversão da absorbância (Lehner et al. 2008). Foram utilizadas três repetições por tratamento;

Enzima catalase - determinada pelo ensaio contendo $100 \mu \mathrm{L}$ do extrato enzimático bruto e $1.400 \mu \mathrm{L}$ de um meio de reação constituído por $900 \mu \mathrm{L}$ de tampão fosfato $50 \mathrm{mM}, \mathrm{pH}$ 7,8 e $500 \mu \mathrm{L}$ de $\mathrm{H}_{2} \mathrm{O}_{2} 0,97 \mathrm{M}$ (Hodges et al. 1997). O decréscimo na absorbância a $240 \mathrm{~nm}$, na temperatura de $25^{\circ} \mathrm{C}$, foi medido a cada 10 segundos, durante dois minutos de reação. A atividade enzimática foi calculada utilizando-se o coeficiente de extinção molar de $36 \mathrm{M} \mathrm{cm}^{-1}$ (Anderson et al. 1995). Uma unidade de atividade (U) foi definida como a quantidade de enzima necessária para converter $1 \mathrm{mmol}$ de substrato em produto por minuto, por $\mathrm{mL}$, nas condições do ensaio. Foram utilizadas três repetições por tratamento.

O delineamento utilizado foi o inteiramente casualizado (DIC). Os resultados foram submetidos a análise de variância (ANOVA), sendo a comparação entre os diferentes tratamentos feita por meio de análises de regressão, ajustando-se modelos de equações lineares e quadráticas, com o auxílio do programa Statistica 7.0 (Statsoft 2008). Os resultados das médias da percentagem de germinação, conteúdo de malonaldeído e atividade da enzima catalase foram correlacionados através do uso de correlação simples, a $5 \%$, pelo teste $\mathrm{F}$.

\section{RESULTADOS E DISCUSSÃO}

A superação da dormência com ácido sulfúrico foi eficiente para promover a germinação das sementes de $P$. nitens, que apresentaram média de $89 \%$ nas sementes sem envelhecimento $\left(\mathrm{T}_{0}\right)$, enquanto, em sementes que não tiveram a dormência superada, a percentagem de germinação no tempo $\mathrm{T}_{0}$ foi de apenas $2 \%$. Nas sementes submetidas à superação da dormência, observou-se redução contínua na percentagem de germinação, ao longo do tempo de envelhecimento acelerado, de modo que sementes envelhecidas por 72 horas apresentaram a menor percentagem de germinação (7\%) (Figura 1).

Nas sementes sem prévia superação da dormência, foi constatado comportamento contrário, com aumento progressivo na germinação, à medida em que se aumentou o período de exposição ao envelhecimento acelerado, chegando a $50 \%$, após 72 horas de envelhecimento.

Segundo Vieira \& Carvalho (1994), o declínio na germinação das sementes submetidas ao envelhecimento acelerado pode ser atribuído à perda da compartimentalização celular e à desintegração do sistema de membranas, promovendo descontrole do metabolismo e das trocas de água e solutos entre as células e o meio exterior. Nas sementes que já tiveram a permeabilidade alterada pela aplicação do ácido sulfúrico, o envelhecimento artificial, possivelmente, causou danos fisiológicos à estrutura interna da semente, associados à inativação térmica e danos ao embrião (Givelberg et al. 1984). Por outro lado, as condições de temperatura e umidade relativa elevadas podem atuar aumentando a permeabilidade do tegumento das sementes intactas (Roberts 1964), resultando no aumento da germinação, onde o tegumento atuaria no sentido de amenizar o aquecimento no interior da semente.

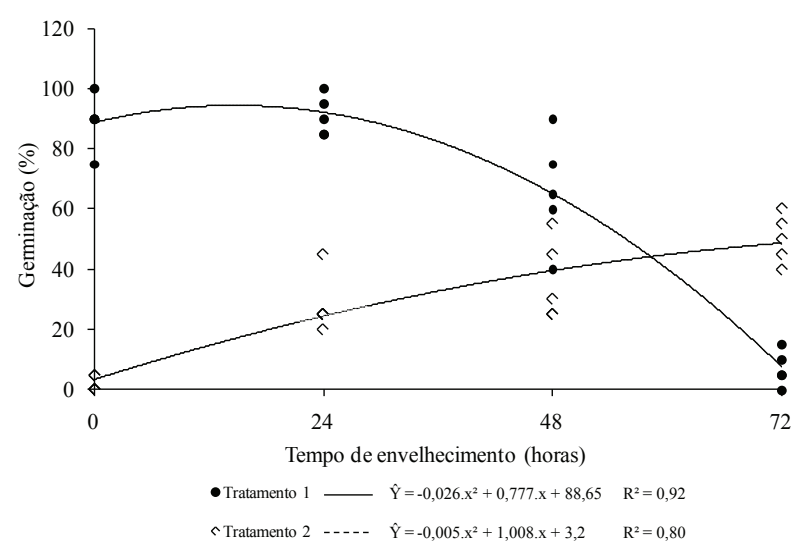

Figura 1. Percentagem de germinação de sementes de $P$. nitens submetidas (Tratamento 1) ou não (Tratamento 2) à superação da dormência, em diferentes tempos de envelhecimento acelerado a $40^{\circ} \mathrm{C}$ (Viçosa, $\mathrm{MG}, 2010$ ). 
O conteúdo de malonaldeído (MDA), considerado um indicador geral da peroxidação de lipídios, manteve-se estável até 24 horas de envelhecimento após a superação da dormência, com valores máximos em 48 horas e redução significativa em 72 horas de envelhecimento artificial (Figura 2).

De acordo com Jeng \& Sung (1994), quando a semente é envelhecida, ocorre maior peroxidação dos lipídios e diminuição na atividade das enzimas removedoras de peróxidos, contribuindo para a perda da viabilidade. Desta forma, o aumento na peroxidação de lipídios, em 48 horas de envelhecimento artificial, indica que este envelhecimento propiciou a deterioração nas sementes de $P$. nitens.

Em sementes de Pinus thunbergii, envelhecidas artificialmente, foram observados altos conteúdos de malonaldeído, os quais foram associados ao aumento da peroxidação de lipídios e à queda na viabilidade das sementes (Kim et al. 2010).

A redução no teor de MDA, em 72 horas de envelhecimento, pode ter duas razões: a primeira seria a morte das sementes, com o metabolismo em baixa, enquanto a segunda poderia ser creditada à ação de enzimas desintoxicadoras, como ocorre pelo ciclo do ascorbato/glutationa, as quais atuariam em paralelo com a enzima catalase e, neste caso, estas enzimas não sofreriam a ação do ambiente estressante do envelhecimento, como a catalase.

Nas sementes sem superação da dormência, o teor de MDA decresceu com a exposição ao envelhe-

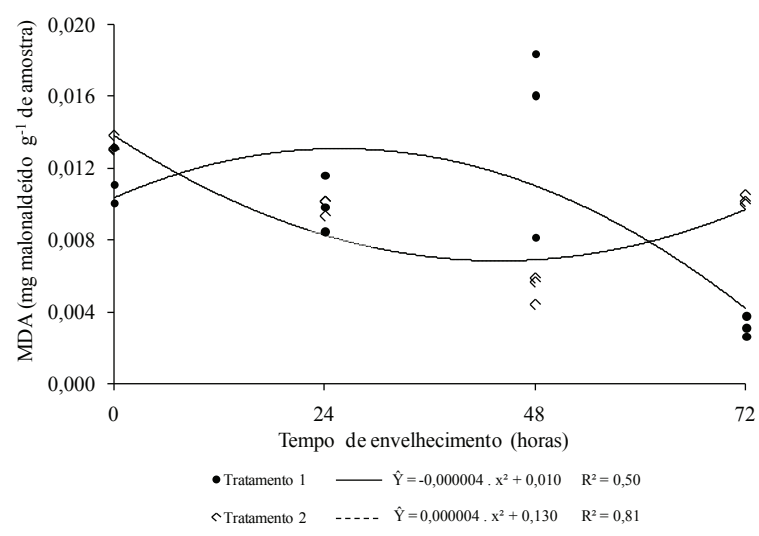

Figura 2. Conteúdo de malonaldeído ( $\mathrm{mg} \mathrm{g}^{-1}$ de amostra) de sementes de $P$. nitens submetidas (Tratamento 1 ) ou não (Tratamento 2) à superação da dormência, em diferentes tempos de envelhecimento acelerado a $40^{\circ} \mathrm{C}$ (Viçosa, MG, 2010). cimento acelerado por até 48 horas. Houve aumento significativo em 72 horas, retornando ao valor de 24 horas, de forma que, nas sementes de $P$. nitens ainda dormentes, a exposição ao envelhecimento artificial acarretou diminuição na peroxidação lipídica até o tempo de 48 horas de envelhecimento, relacionando-se ao aumento da percentagem de germinação, neste período. Em 72 horas de envelhecimento artificial, o novo acréscimo na peroxidação de lipídios pode estar relacionado ao início de deterioração destas sementes, devido ao longo tempo de exposição à temperatura e umidade relativa elevadas, ainda que não tenha sido constatada redução na germinação. Dentre as várias consequências relacionadas ao processo de deterioração das sementes, a queda na germinação tem sido apontada como um dos últimos eventos que caracterizam o declínio na qualidade fisiológica de sementes (Paiva et al. 2008).

Os resultados da atividade da enzima catalase, em sementes com dormência superada, encontram-se na Figura 3, onde se pode perceber a redução contínua e significativa, com o decorrer do tempo de envelhecimento, com a atividade da enzima mínima em 72 horas de envelhecimento artificial. Por outro lado, nas sementes onde não foi superada a dormência, a atividade da catalase não se alterou significativamente.

Nas sementes que tiveram a dormência superada, a atividade da enzima, nas primeiras 24 horas, é, aparentemente, suficiente para manter o teor de MDA estável, uma vez que a sua concentração também se

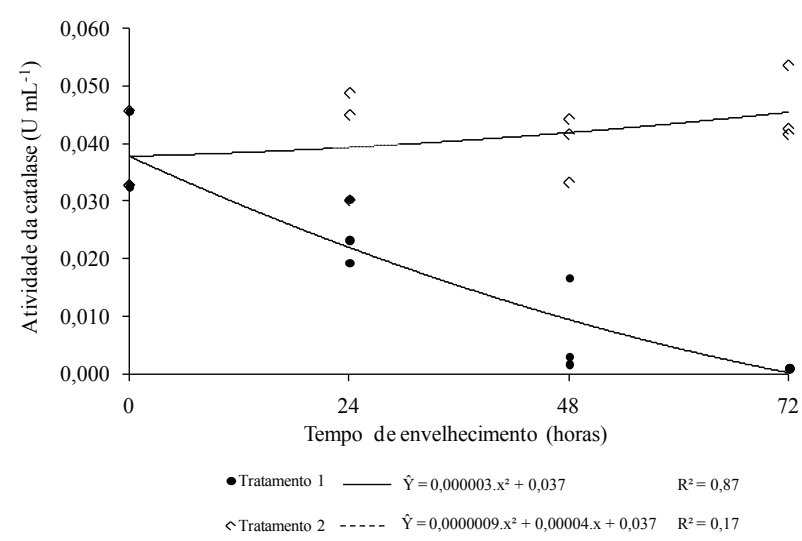

Figura 3. Atividade da enzima catalase $\left(\mathrm{U} \mathrm{mL}^{-1}\right)$, em sementes de $P$. nitens submetidas (Tratamento 1 ) ou não (Tratamento 2) à superação da dormência, em diferentes tempos de envelhecimento acelerado a $40^{\circ} \mathrm{C}$ (Viçosa, MG, 2010). 
mantém sem alterações significativas, com aumento apenas em 48 horas de envelhecimento. No entanto, a partir deste tempo, percebe-se que a redução na atividade da enzima catalase associa-se à diminuição significativa do potencial germinativo das sementes de $P$. nitens, indicando que o envelhecimento artificial resultou em danos ao funcionamento e à estrutura celular. Resultados semelhantes foram observados por Cakmak et al. (2010), Demirkaya et al. (2010) e Chauhan et al. (2011), onde a diminuição da atividade das enzimas antioxidantes, durante o envelhecimento, resultaram em menor viabilidade e vigor das sementes. Tal situação reforça a suposição de que a catalase tem papel importante no controle de elementos reativos ao oxigênio, agindo em consonância com outros ciclos, como o ciclo ascorbato/glutationa. Uma diminuição das enzimas antioxidantes está ligada ao aumento de peroxidação lipídica e envelhecimento acelerado, com relação positiva entre a capacidade antioxidante da enzima e o vigor da semente (Bailly et al. 1996 e 2002).

Nas sementes que não tiveram a dormência superada, percebe-se situação distinta, onde a ação da catalase permanece inalterada, enquanto o acúmulo de MDA decresce, significativamente, até 48 horas de envelhecimento, aumentando, significativamente, em 72 horas. Dessa forma, a não superação da dormência, com consequente manutenção da barreira tegumentar ao envelhecimento, atuou como empecilho à diminuição do vigor e atividade da catalase. Tanto é assim que, mesmo sem diferença na atividade da catalase, durante o envelhecimento, o teor de MDA aumenta para o mesmo patamar que o de 24 horas. É possível que tenha havido inibição da atividade do ciclo do ascorbato/glutationa, o que permitiu tal aumento.

Foram observadas correlações positivas significativas entre as médias de germinação e os valores da atividade da enzima catalase e do conteúdo de malonaldeído nas sementes, após superação da dormência (Tabela 1), indicando que o comportamento da variável germinação pode ser associado às alterações nas variáveis MDA e CAT, durante o envelhecimento artificial destas sementes. Comparando-se os coeficientes de correlação simples, nos tratamentos sem superação da dormência, verifica-se que estes foram não significativos, a 5\%, de forma que, quando há manutenção da dormência nas sementes, o desempenho germinativo, após o envelhecimento artificial, não pode ser explicado em resposta às variáveis analisadas.
Tabela 1. Coeficientes de correlação simples (r) entre os valores médios de germinação $(\mathrm{G})$, conteúdo de malonaldeído (MDA) e atividade da enzima catalase (CAT), em sementes de $P$. nitens submetidas (Tratamento 1) ou não (Tratamento 2) à superação da dormência, em diferentes tempos de envelhecimento acelerado a $40^{\circ} \mathrm{C}$ (Viçosa, MG, 2010).

\begin{tabular}{lccc}
\hline \multicolumn{4}{c}{ Tratamento 1 } \\
\hline G & G & MDA & CAT \\
\hline MDA & - & $0,66^{*}$ & $0,77^{*}$ \\
CAT & $0,66^{*}$ & - & $0,28^{\text {ns }}$ \\
\hline \multicolumn{4}{c}{ Tratamento 2} \\
\hline G & $0,77^{*}$ & $0,28^{\text {ns }}$ & - \\
\hline MDA & G & MDA & CAT \\
CAT & - & $-0,55^{\text {ns }}$ & $0,32^{\text {ns }}$ \\
\hline
\end{tabular}

$* \mathrm{e}^{\text {ns }}$ Significativo a $5 \%$ e não significativo, respectivamente, pelo teste $\mathrm{F}$.

\section{CONCLUSÕES}

1. Alterações fisiológicas e na atividade da enzima catalase relacionam-se à diminuição da qualidade fisiológica de sementes de Pterogyne nitens envelhecidas artificialmente, após superação da dormência tegumentar.

2. Em sementes sem prévia superação da dormência, não há relação entre teores de malonaldeído, atividade da catalase e perda da qualidade de sementes de $P$. nitens, quando submetidas ao envelhecimento acelerado.

\section{REFERÊNCIAS}

ANDERSON M. D.; PRASAD, T. K.; STEWART, C. R. Changes in isozyme profiles of catalase, peroxidase, and glutathione reductase during acclimation to chilling in mesocotyls of maize seedlings. Plant Physiology, Madison, v. 109, n. 4, p. 1247-1257, 1995.

ARAÚJO, J. M. A. Química de alimentos: teoria e prática. Viçosa: UFV, 1995.

BAILLY, C. et al. Changes in activities of antioxidant enzymes and lipoxygenase during growth of sunflower seedlings from seeds of different vigour. Seed Science Research, Wallingford, v. 12, n. 1, p. 47-55, 2002.

BAILLY, C. et al. Changes in malondialdehyde content and in superoxide dismutase, catalase and glutathione reductase activities in sunflower seeds as related to deterioration during accelerated aging. Physiologia Plantarum, Lund, v. 97, n. 1, p. 104-110, 1996. 
BOWLER, C.; VAN MONTAGU, M.; INZÉ, D. Superoxide dismutase and stress tolerance. Annual Review of Plant Physiology and Plant Molecular Biology, Danvers, v. 43, n. 2, p. 83-116, 1992.

CAKMAK, T. et al. Natural aging-related biochemical changes in alfalfa (Medicago sativa L.) seeds stored for 42 years. International Research Journal of Plant Science, Sapele, v. 1, n. 1, p. 1-6, 2010.

CARVALHO, P. E. R. Espécies florestais brasileiras: recomendações silviculturais, potencialidades e uso da madeira. Brasília, DF: Embrapa Colombo - CNPF, 1994.

CHAUHAN, D. S. et al. Change in storage enzymes activities in natural and accelerated aged seed of wheat (Triticum aestivum). Indian Journal of Agricultural Sciences, Nova Delhi, v. 81, n. 11, p. 1037-1040, 2011.

CORTE, V. B. et al. Qualidade fisiológica de sementes de Melanoxylon brauna envelhecidas natural e artificialmente. Scientia Forestalis, Piracicaba, v. 38, n. 86, p. 181-189, 2010.

DELOUCHE, J. C. An accelerated aging technique for predicting relative storability of crimson clover and tall fescue seed lots. Agronomy Abstracts, Réduit, v. 40, n.1, p. $40,1965$.

DEMIRKAYA, M.; DIETZ, K. J.; SIVRITEPE, H. O. Changes in antioxidant enzymes during aging of onion seeds. Notulae Botanicae Horti Agrobotanici, ClujNapoca, v. 38, n. 1, p. 49-52, 2010.

FOOD AND AGRICULTURE ORGANIZATION (FAO). Panel of experts in forest gene resources. Roma: FAO, 1996.

GIVELBERG, A.; HOROWITZ, M.; POLJAKOFFMAYBER, A. Solute leakage from Solanum nigrum L. seeds exposed to high temperatures during imbibition. Journal of Experimental Botany, Oxford, v. 35, n. 161, p. 1754-1763, 1984.

HODGES, D. M. et al. Antioxidant enzyme responses to chilling stress in differentially sensitive inbred maize lines. Journal of Experimental Botany, Oxford, v. 48, n. 310, p. 1105-1113, 1997.

JENG, T. L.; SUNG, J. M. Hydration effect on lipid peroxidation and peroxide scaveging enzymes activity of artificially aged peanut seed. Seed Science and Technology, Zürich, v. 22, n. 3, p. 531-539, 1994.

KIM, D. H.; HAN, S. H.; LEE, J. C. Germination and biochemical changes in accelerated aged and osmoprimed Pinus thunbergii seeds. Journal of the Korean Forestry Society, Chunchon, v. 99, n. 2, p. 244-250, 2010.

KRUSE, N. D. et al. Estresse oxidativo em girassol (Helianthus annuus) indica sinergismo para a mistura dos herbicidas metribuzin e clomazone. Planta Daninha, Viçosa, v. 24, n. 2, p. 379-390, 2006.

LEHNER, A. et al. Changes in soluble carbohydrates, lipid peroxidation and antioxidant enzyme activities in the embryo during ageing in wheat grains. Journal of Cereal Science, Melbourne, v. 47, n. 3, p. 555-565, 2008.

LIMA, E. S.; ABDALLA, D. S. P. Peroxidação lipídica: mecanismos e avaliação em amostras biológicas. Revista Brasileira de Ciências Farmacêuticas, São Paulo, v. 37, n. 3, p. 1-11, 2001.

MARCOS FILHO, J. Teste de envelhecimento acelerado. In: KRZYZANOWSKI, F. C.; VIEIRA, R. D.; FRANÇA NETO, J. B. (Eds.). Vigor de sementes: conceitos e testes. Brasília, DF: Abrates, 2005. p. 1-24.

MIRA, S. et al. Biochemical changes induced in seeds of Brassicaceae wild species during ageing. Acta Physiologiae Plantarum, Cracóvia, v. 33, n. 5, p. $1803-$ 1809, 2011.

NASSIF, S. M. L.; PEREZ, S. C. J. G. A. Germinação de sementes de amendoim-do-campo (Pterogyne nitens Tul.): influência dos tratamentos para superar a dormência e profundidade de semeadura. Revista Brasileira de Sementes, Pelotas, v. 19, n. 2, p. 171-178, 1997.

NOGUEIRA, J. C. et al. Estudo de progênies e procedências de Pterogyne nitens Tull. Boletim técnico do Instituto Florestal, São Paulo, v. 40a, n. 2, p. 357-366, 1986.

PAIVA, A. S. et al. Qualidade física e fisiológica de sementes da leguminosa forrageira Macrotyloma axillare cv. Java. Revista Brasileira de Sementes, Pelotas, v. 30, n. 2, p. 130-136, 2008.

ROBERTS, H. A. Emergence and longevity in cultivated soil of seed of some annual weeds. Weed Research, Malden, v. 4, n. 4, p. 296-307, 1964.

SCANDALIOS, J. G. Oxidative stress: molecular perception and transduction of signals triggering antioxidant gene defenses. Brazilian Journal of Medical and Biological Research, Ribeirão Preto, v. 38, n. 7, p. 995-1014, 2005.

SCANDALIOS, J. G. Oxygen stress and superoxide dismutases. Plant Physiology, Madison, v. 101, n. 1, p. 7-12, 1993.

SCHWEMBER, A.; BRADFORD, K. J. Quantitative trait loci associated with longevity of lettuce seeds under conventional and controlled deterioration storage conditions. Journal of Experimental Botany, Oxford, v. 61, n. 15, p. 4423-4436, 2010.

SILVA, L. M. M. et al. Morfologia de frutos, sementes e plântulas de Luetzelburgia auriculata Duck. (pauserrote) e Pterogyne nitens Tul. (madeira nova do brejo) Leguminosaceae. Revista Brasileira de Sementes, Pelotas, v. 17, n. 2, p. 154-159, 1995.

STATSOFT INC. Statistica data analysis system version 8.0. Tulsa: Statsoft Inc., 2008.

VIEIRA, R. D.; CARVALHO, N. M. Testes de vigor em sementes. Jaboticabal: Funep/Unesp, 1994. 